\title{
Unfinished Business: The Role of Research in Family Medicine
}

\author{
Robin S. Gotler, MA \\ Case Western Reserve University, \\ Cleveland, Ohio
}

Conflicts of interest: the author reports none

\section{CORRESPONDING AUTHOR}

Robin S. Gotler, MA

Case Western Reserve University

11000 Cedar Ave, Suite 402

Cleveland, $\mathrm{OH} 44106$

rsgotler@gmail.com

\begin{abstract}
Although the generation of new knowledge through research is a hallmark of medical specialties, research was a low priority in family practice when it was established in 1969. Today, when a base of knowledge is crucial to the ability to lead health care change, the early relationship between family practice and research continues to influence the specialty. An examination of archival and secondary materials finds that the priority placed on research during family practice's early years was shaped by internal and external factors, including, (1) family physicians' desire to differentiate themselves from the prevailing specialty environment; (2) lack of a clear identity in family practice; (3) the non-laboratory nature of family medicine research; (4) reliance on information from other specialties; and, (5) a focus on establishing an academic presence. The low level of attention given to research during the early years of family practice has had lasting implications, as the specialty seeks to transform practice while continuing to struggle to achieve academic acceptance. A strong culture of generalist knowledge is crucial in assuring family medicine's future and strengthening its ability to improve the health of individuals, families, and communities.
\end{abstract}

Ann Fam Med 2019;17:70-76. https://doi.org/10.1370/afm.2323.

W hen family practice became a medical specialty in 1969, Edward Kowalewski, MD, president of the American Academy of General Practice, implored his colleagues to embrace research: "An urgent need exists to shore up our branch of the profession with a specific scientific foundation... We must discard the age-old attitude of the family physician as an unscientific, bedside-manner specialist ...I plead for recognition of the urgency of this effort."

Although Kowalewski's belief in research was deeply felt, it was not widely shared. In the 1960s to 1970s, family practice leaders undertook major tasks to establish a medical specialty, developing residency programs, certifying exams, and academic infrastructure. They did not, however, establish an active program of research, in spite of the central role of research in American medicine. ${ }^{2}$

This paper explores the low status of research in the early years of family practice. It is not a comprehensive history of research in the discipline. Rather, through exploration of published literature, archival materials, and secondary sources, it examines the research environment during a particular period of time - the 1950s to 1970s - to provide context for the specialty's 21 st century commitment to transforming health care and health. ${ }^{3}$

\section{THE RISE OF A NEW SPECIALTY}

In the mid-1900s, as medical specialists, new technologies, and hospitals grew in numbers and prestige, general practitioners (GPs) were increasingly viewed as outdated. Americans viewed specialization as progress, ${ }^{4}$ but by the 1960s admiration was tinged with disillusion and contempt. It was increasingly difficult to find a primary care physician, and there was a sense that, as science and technology advanced, medicine was losing its humanity. 
While the 20th century has seen a tremendous burgeoning of scientific medicine, a splendid proliferation of specialized talent in medicine, and an almost unimaginable refinement of the medical armamentarium, it has also witnessed the withering away of the family physician function, a disturbing alienation of physicians from society, and a growing disenchantment on the part of many thoughtful people concerning the medical profession's response to the needs of people for medical care. ${ }^{5}$

Three influential reports ${ }^{6-8}$ helped create public and political momentum for a new approach to medicine and "a new kind of specialist."7(p.1) In the new specialty, named family practice (later renamed family medicine), physicians served as patients' first contact with the health care system; evaluated their health care needs; and provided comprehensive, continuous care in family and community contexts. Residency training allowed family physicians to stay relevant and economically viable, ${ }^{9}$ but survival was not their only motive. Family practice had a mission. It intended to be an antidote to narrowly-focused specialties, treating patients as whole people whose health needs included compassion and understanding. According to family physician G. Gayle Stephens, "We simply do not believe that all health problems have technological solutions... Human illness and suffering happens to the entire organism, the self that laughs and cries, and science is applicable to only a part of the self." ${ }^{\prime 10}$

By rejecting medicine's prevailing focus on more limited specialties, family practice fit well with the ethos of the 1960s and 1970s, an era in which traditional institutions were challenged. During this time, "The economic and moral problems of medicine displaced scientific progress at the center of public attention," ${ }^{\prime \prime(p .379)}$ and public views of research shifted. Research became emblematic of depersonalized medicine, and researchers were portrayed as greedy and aggressive, concerned with "glorify[ing the]... ivory tower as a research center $^{\prime \prime 11}$ rather than caring for patients.

Many general practitioners shared these negative views. As they lost influence and status, GPs expressed resentment toward medical schools, specialists, and researchers. According to J.A. Cosgriff Jr, president of the Minnesota chapter of the American Academy of General Practice,

When the medical school gauges its excellence by the number of professors and department heads it produces, or the sum of research monies it is annually awarded, rather than by the increasing number of family physicians it might train to meet the immediate needs of patients, a serious imbalance exists. Of course research is necessary. But it can and is becoming overvalued. ${ }^{12}$

Family practice intended to renew the focus on patient care, with research as a necessary but second- ary element. As described by an educator in 1969, the family physician was "more [of] an 'artist' in dealing with others and their problems - a healer-rather than a 'scientist' dealing with disease processes or malfunctioning organs...he sees [science] as a means to an end rather than as an end in itself."13

\section{ISSUES OF IDENTITY}

The patient care mission was a guiding light for family practice, but defining the specialty to others proved a challenge. Unlike specialties that dealt with a single organ or technique, the purview of family practice was less clear. According to a family physician in 1974,

There is still great confusion as to the true nature of this new discipline... even some teachers of family medicine seem to have failed to grasp the fundamental concepts of their specialty. One director of a family medicine residency program recently confessed, "The heads of the other departments ask me, 'What can your doctors do that specialists can't do better?' And I don't know what to tell them." ${ }^{14}$

Before family practice was formally established, the medical community debated possible names. Eventually, 2 were adopted: family medicine (distinct from internal medicine) referred to the specialty's knowledge base, and family practice (distinct from general practice) referred to the application of knowledge to patient care. Multiple definitions were put forth for these terms, reflecting lack of consensus about the new specialty's direction and lack of clarity about what it had to offer. The terminology debate had broader implications as well. Separating patient care (family practice) from intellectual and academic pursuits (family medicine) suggested that the specialty could not integrate both. Two educators wrote,

... a conflict exists between meeting the immediate needs of the primary care shortage and providing for the long-term development of family medicine as a discipline... it appears that the pressures to produce personal, comprehensivecare physicians have led the family-practice movement to concentrate on contributing short-term relief for the care delivery system...while sacrificing the development of its own unique potential as the most important applied arm of family medicine. ${ }^{15}$

Without a consensus view of family practice, there was little agreement about if and how research should be conducted. Those who viewed family medicine as a unique science believed that research was essential. Yet to those who viewed family practice as a solution to the primary care shortage, research was sometimes deemed irrelevant or even harmful.

Some of our staunchest protagonists believe that research is foreign to family practice and appropriate only to the 
tertiary medical center and its laboratories. Research in our teaching programs, it is argued, may handicap the growth and even distort family practice, drawing it away from its essential grassroots interest in the commonly occurring problems of health and disease. ${ }^{16}$

\section{THE NATURE OF PRACTICE-BASED RESEARCH}

Just as family physicians envisioned a different, more patient-centered form of care, family medicine researchers envisioned scientific inquiry that differed from the medical mainstream. Practice-based researchers such as British GP Ian McWhinney, family physician John Geyman, pediatrician Robert Haggerty, and internist Kerr White anticipated not only clinical trials but also inquiry by networks of practices ${ }^{17}$ and descriptive studies based on the work of such 18th and 19th century figures as Edward Jenner and James Mackenzie. ${ }^{18}$ The strength of family medicine research was its base in practice, with the practice as a type of laboratory in which "the observer works within rather than outside the sphere of his observed world."19 Yet to those outside the specialty, practice-based research bore little resemblance to the laboratory achievements of such contemporary heroes as Jonas Salk. According to a hospital-based physician, "when one talks about research... immediately the next association that comes is the laboratory...the whole climate serves to minimize the value of nonlaboratory research."20

Family medicine's commitment to practice-based research opened the door to a broad range of exploration including clinical, health services, behavioral, and educational topics. By the mid-1980s, the Hames Consortium, a series of think tanks, developed a list of 100 research questions best addressed by family medicine. ${ }^{21}$ To address these questions, however, researchers faced complex challenges in developing appropriate methods and tools. There was an overwhelming array of possible methods and approaches available from other disciplines, eg, the social sciences and epidemiology, but new tools and infrastructure applicable to primary care were also needed. This included systems for classifying health problems, standard terminology for gathering basic data, tools to measure relevant outcomes, and uniform methods of describing practice demographics-long-term tasks vital to the development of the research endeavor. Furthermore, focusing on patients and conditions as they presented to family physicians - undifferentiated and undiagnosed - meant that health and illness were often evolving, patient-specific phenomena, presenting particular challenges for capturing and analyzing data.

Although family medicine researchers recognized the complexity of generalist inquiry, laboratory scientists and funding agencies did not. To them, practice-based research appeared simplistic and outdated, an attitude which was reflected in funding. By 1973, 54\% of the National Institutes of Health's allocations went to the National Cancer Institute, National Heart, Lung, and Blood Institute, and National Institute of Arthritis, Diabetes, and Digestive and Kidney Diseases. ${ }^{22}$ In addition, funding was usually awarded to medical schools and hospitals, where GPs had had little presence and family physicians struggled for respect. In 1980, with appropriations of more than $\$ 3$ billion, ${ }^{23}$ the NIH awarded 2 grants totaling $\$ 133,000$ to studies with principal investigators from family practice departments. ${ }^{24}$

One notable exception was family physician Curtis Hames, whose cardiovascular disease study was funded by NIH from 1958-1995. Conducted in collaboration with an epidemiology department, the study was based on Hames's observation that heart disease was more prevalent in white than black patients, although blacks had higher rates of hypertension and higher-fat diets. His work came to the attention of NIH director James Watt and an almost 40 -year partnership ensued. ${ }^{25}$

This collaboration was a rarity. To the medical community, scientific inquiry by family physicians did not usually qualify as fundable research. The reception was often no better within family practice where research was "a forbidden word viewed by many family physicians as irrelevant." 26

\section{"THE ERA OF SYNTHESIS"27}

Although research had limited appeal in family practice, the specialty embraced ongoing education and learning. Many family physicians believed that as leaders of health care teams, they required a broad range of information synthesized into an easy-to-use, coherent body of knowledge. In fact, such information already existed. GP, the widely-read publication of the American Academy of General Practice, aimed to omit "the esoteric gobbledegook," focusing on "how-to-do-it articles $^{\prime 28}$ from a wide range of specialties and disciplines. Edited by Walter C. Alvarez, MD, recognized for his work on the physiology of the digestive tract, $G P$ was well-received for its "concisely presented material for the tired general practitioner."29

Synthesized information from other disciplines served an important function, but, to research proponents, it did not replace generalist inquiry. According to John Geyman, "The capacity to reduce existing clinical knowledge and procedures to readily understandable and recallable dimensions has... been central to the 'mind set' of the general practitioner, which has left the responsibility for development of new knowledge to other specialties... and has prevented the recognition of 
general practice itself as a legitimate object of critical inquiry. ${ }^{\prime 30}$ Without a unique body of knowledge by and for family physicians, "the standards for 'good' practice were drawn directly from other clinical disciplines." ${ }^{\text {"30 }}$

It is important to note that, although specialties outside general practice helped guide the discipline's information needs, several pioneers laid the foundation for intellectual development in family practice. Ian McWhinney set out principles to advance the science of family medicine focusing on technique, philosophy, and natural history. ${ }^{31}$ Gayle Stephens argued that patient management was "the intellectual and academic basis for family practice... our agenda for research." ${ }^{132}$ In 1972, family physician Maurice Wood and a group of investigators met to address the urgent need for standards in coding and classifying primary care conditions and procedures, which led to the development of the North American Primary Care Research Group (NAPCRG), a nexus of research in family medicine. In 1974, John Geyman became the first editor of the Journal of Family Practice (JFP), which aimed to expand the specialty's base of knowledge. Geyman set out to publish original research for and "from the family physician's particular perspective," ${ }^{\prime \prime 3}$ and JFP went on to serve a vital role, moving "beyond the usual... literature in the field, which tends to be derivative in nature from other clinical disciplines." ${ }^{\text {34 }}$

While these leaders, and others, addressed the intellectual development of family practice, the new specialty's anti-intellectual image persisted. At a time when mid-20th century scientist-researchers were described as having, "Profound intellectual curiosity and analytic thought," ${ }^{\prime 35}$ family practice was often viewed as "left behind in the triumphant march of scientific development."136

\section{INSTITUTIONAL PRIORITIES}

Although many family physicians were satisfied with synthesized information from other specialties, AAGP president Edward Kowalewski was not. Kowalewski believed research was essential to family practice. In his 1969 inauguration speech, however, he expressed frustration with the level of attention to research:

There was a startling realization [in establishing the specialty] that we needed to build a body of special knowledge that could be transferred from one family physician to another, a basic body of knowledge from which all future progress in our family-practice discipline could emanate.... although the $[\mathrm{A}]$ cademy has delved into some research activities...we have done so in a piecemeal, uncorrelated fashion...not really knowing what group within the organization should handle a given project, nor where responsibility should lie. ${ }^{1}$
Although the Academy's research activities were modest in the early 1970s, a more active period of research ensued in 1978 with the restructuring of its Committee on Clinical Investigation. The Society of Teachers of Family Medicine (STFM), established in 1967, recognized the importance of research and soon sought to help develop faculty members' research skills. NAPCRG continued to provide a leading voice for family medicine research and had more than 700 members by the early 1980 s. $^{37}$

In spite of this progress, interest in family medicine research remained limited. In 1979-1980, among more than three-quarters of family practice programs, 185 family physicians $(1.3 \%)$ spent more than $10 \%$ of their time in research. ${ }^{37}$ It is perhaps not surprising, then, that STFM's Research Committee Chair commented in a letter (February 29, 1980) that, "family medicine has as yet failed to establish its intellectual legitimacy."

If research was of limited concern in the 1970s, establishing an academic presence was among the specialty's highest priorities, with such challenging tasks as creating curricula, establishing residency programs, and recruiting and training faculty. For family medicine, however, academia presented additional challenges. In many medical schools and hospitals, family medicine was portrayed as anti-intellectual and family physicians as unqualified, images that furthered political agendas ${ }^{38}$ as specialties vied for power and funding. As a result, family physicians were often not credible or welcome in medical schools. "The most frequently repeated question of skeptics and critics of family medicine, their favorite put-down, is this: What domain of knowledge, skills or method is unique to family medicine? Is it not simply a diluted mixture of the well-established specialties applied to the simpler self-limited clinical disorders?"39 According to another description, "Medical school faculties have characterized or caricaturized family medicine and even primary care as being unscientific and generally practiced by those unable to withstand the rigors of logic and reason. ${ }^{\prime 40}$

To many academics, family medicine was an interloper, entering academia not because it was needed, but because of public, political, and professional pressures. In 1969, internist Thomas Brem, president of the Advisory Board for Medical Specialties, stated that family care was best provided by internists and pediatricians, despite the vote to approve the new specialty: "There has been no change in our philosophy...We have just become more permissive. Largely because of the public demand...we have decided to give family practice specialization a try." ${ }^{\prime \prime 1}$ Nine years later, internist Edmund Pellegrino observed: "Family medicine has made something of a forced entry into medical education. It has been aided by the convergence of some 
powerful forces external to academia... Past experience shows that even such powerful forces may not suffice to ensure long-term academic survival." ${ }^{\prime 39}$

In addition to being viewed as an intruder, the specialty's mission made it a difficult fit. Family medicine sought to meet social need through science, but in medical schools, science and social mission were separate and unequal pursuits. According to a family physician/academic in 1973, "the problem was not so much that scientifically oriented academic medicine is incompatible with socially responsible family medicine, but... the ardent advocates of each frequently are... it would be less than candid to suggest that an overwhelming number of today's medical school faculty are enthusiastic about family medicine." ${ }^{\prime \prime 2}$

Development of a well-supported research agenda might have helped family medicine gain the academic, intellectual, and scientific credibility it needed and desired, yet research was not a widely considered strategy. In the face of a hostile environment, the specialty turned to its mandate to increase access to primary care.

Establishment of family medicine as a peer group in the academic world is not easy... To accomplish this we must formulate our approach solely on the basis of the needs of our people. This is an invulnerable position... [it] provides you with objectivity and an indestructible weapon... ${ }^{43}$

Patient care was family practice's mission and expertise. A 1970 survey of over 2,000 candidates for family practice board certification found that $4 \%$ had major involvement in teaching or research, while 93\% were in private practice. ${ }^{44}$ The specialty focused on this strength, which had the full force of the American public behind it. According to Pellegrino, "While [a research presence] is highly desirable and will enhance academic acceptance, it is not primary to the academic claim of family medicine. Research efforts will develop only after academic family medicine gains more confidence and a stronger foothold in the academic community." ${ }^{139}$ This belief was reflected in the priorities set by family practice leaders. In the absence of strong institutional guidance and support, research lagged behind, as Geyman noted in 1978:

Although scattered reports of noteworthy research in family practice have been published... the over-riding priority... to date has involved the organization and development of teaching programs. Visible and respected examples of research programs and researchers have not yet been developed in most family-practice settings. ${ }^{45}$

\section{CONCLUSION}

Family practice sought to bring wholeness and humanity to medicine at a time when high tech, fragmented care prevailed. In distinguishing itself from medicine's status quo, it set itself apart from science and research. Challenges in establishing a research agenda included an unclear identity, competing priorities within the specialty, the unique nature of practice-based research, limited methods and tools, and limited interest in research among family physicians.

In the decades since family medicine became a specialty, however, there has been important progress in research. The dedication and passion of a small group of early researchers has led to an increasingly large, sophisticated, and successful research endeavor. Federal funding has increased slightly ${ }_{1}^{46}$ while institutional support from such organizations as NAPCRG, the American Academy of Family Physicians, the AAFP Foundation, the American Board of Family Medicine, and the ABFM Foundation ${ }^{47}$ has increased substantially. There is growing recognition, within and outside the specialty, that research from a family medicine perspective matters. Practice-based research networks, whose members provide care to $15 \%$ of the US population, have become essential to generating new knowledge about clinical practice, public health, and health systems. ${ }^{48}$ Family medicine researchers have significant roles in translational research, evidence-based medicine, and health services research, utilizing new methods and theories as they explore the complexity of health and health care.

Yet the low status of research in the specialty's early years continues to resonate. Although family medicine is essential to the US health care system, "research remains a particular challenge to the profession, and family physicians are minimally involved with the National Institutes of Health compared with other specialties." ${ }^{\prime 49}$ Given the fragmented and narrowly focused system in which family medicine exists, ${ }^{50}$ it is perhaps not surprising that the specialty is still challenged by integrating research into its patient care-oriented culture.

How, then, can family medicine build on its progress and develop a "body of knowledge that defines our discipline?"51 History suggests this will involve a range of approaches. First, those involved in research can continue efforts to close the long-perceived gap between inquiry and practice. This requires removing "the cloak of mystery from research"52 by emphasizing the alignment between the domains of family medicine practice and the conceptual framework of its research endeavor. ${ }^{53}$ Second, we can ensure that research is a core element of family medicine's hard-earned academic presence across the discipline. New programs, such as the transdisciplinary Building Research Capacity initiative of the Association of Departments of Family Medicine and $\mathrm{NAPCRG}^{54}$ are important steps in 
moving toward a research infrastructure that is "ready to answer new questions in the real world and in real time." ${ }^{25}$ Third, family medicine researchers can think not only locally-exploring the important problems and questions in everyday practice - they can also think broadly, engaging new partners, methods, and dissemination channels, with fresh thinking about the relevance, rigor, and replicability of their work. ${ }^{56}$

The long-standing issue of what constitutes family medicine's research agenda has yet to be resolved, but researchers are creatively exploring the question and finding common ground. ${ }^{55}$ Thus, while family medicine continues to have unfinished business - the need to incorporate a strong ethos of generalist inquiry into the specialty-new energy, insight, and resources are bringing that vision closer to reality.

The history of research in family medicine illuminates the specialty's past and present while shaping its future. As clinicians, administrators, and policy makers strive for meaningful transformation of primary care practice, a base of family medicine knowledge is an essential ingredient. A research enterprise that encompasses the patient-centered focus on which family medicine was developed can help create not only a strong and vital primary care workforce, but a more humane and effective health care system.

To read or post commentaries in response to this article, see it online at http://www.AnnFamMed.org/content/17/1/70.

Funding support: This study was supported by a fellowship grant from the Center for the History of Family Medicine of the AAFP Foundation.

Acknowledgments: Sincere thanks to John Frey, Larry Green, and Kurt Stange, who provided helpful comments on earlier drafts of this paper; Virginia Barzan and the Minnesota Academy of Family Physicians for access to journal articles; and the Center for the History of Family Medicine for support and invaluable access to archival documents. Thanks also to anonymous peer reviewers for their helpful insights and suggestions.

\section{References}

1. Kowaleski EJ. Inauguration speech. Colorado GP. 1969;11(4):4-8.

2. Ludmerer KM. Learning to Heal. The Development of American Medical Education. New York, NY: Basic Books; 1985:260-265.

3. Puffer JC, Borkan J, DeVoe JE, et al. Envisioning a new health care system for America. Fam Med. 2015;47(8):598-603.

4. Starr P. The Social Transformation of Medicine. New York, NY: Basic Books; 1982:335-338.

5. Bryan JE. The Role of the Family Physician in America's Developing Medical Care Program. St. Louis, MO: Warren H. Green, Inc; 1968:5.

6. Citizens Commission on Graduate Medical Education. The Graduate Education of Physicians. Chicago, IL: American Medical Association; 1966.

7. American Medical Association Ad Hoc Committee on Education for Family Practice. Meeting the Challenge of Family Practice; the Report of the Ad Hoc Committee on Education for Family Practice of the Council on Medical Education. Chicago, IL: American Medical Association; 1966.
8. NCCHS. Health is a Community Affair-Report of the National Commis sion on Community Health Services (NCCHS). Cambridge, MA: Harvard University Press; 1967.

9. Tobbell D. Plow, town, and gown: the politics of family practice in 1960s America. Bull Hist Med. 2013;87(4):648-680.

10. Stephens GG. Family medicine as counterculture. Fam Med Times. 1979:17.

11. The University medical school-its obligations [Executive Directors [sic] Page]. Medical Diggings. 1962;Sep-Oct:10.

12. Cosgriff JA Jr. Reflections on the medical school. Medical Diggings. 1963; Jan-Feb:17-18.

13. Wilson V. Specialist in family practice-prototype of a doctor. GP. 1969;40(2):151-157

14. Baker C. What's different about family medicine? J Med Educ. 1974; 49(3):229-235.

15. Ransom DC, Vandervoort HE. The development of family medicine. Problematic trends. JAMA. 1973;225(9):1098-1102.

16. Smith R. John Fry-researcher in family practice. J Fam Pract. 1975; 2(5):323.

17. Green LA, Wood M, Becker L, et al. The Ambulatory Sentinel Practice Network: purpose, methods, and policies. J Fam Pract. 1984; 18(2):275-280.

18. MCWhinney IR. The naturalist tradition in general practice. J Fam Pract. 1977;5(3):375-378.

19. Eimerl TS, Laidlaw AJ, eds. A Handbook for Research in General Practice. Edinburgh, Scotland: E \& S Livingstone Ltd; 1969:1.

20. Group Health Insurance, Inc. The Future of the Personal Physician. New York, NY: Group Health Insurance, Inc; 1963:99.

21. Hames Consortium: One hundred most important family medicine research questions. Located at: Curtis G. Hames, Sr Papers, Greenblatt Library, Georgia Regents University, Augusta, GA; 1985.

22. Ginzburg E, Dutka AB. The Financing of Biomedical Research. Baltimore, MD: The Johns Hopkins University Press; 1989:29.

23. National Institutes of Health Office of Budget. Appropriations History by Institute/Center (1938 to Present). https://officeofbudget. od.nih.gov/pdfs/FY08/FY08\%20COMPLETED/appic3806\%20-\%20 transposed\%20\%2080\%20-\%2089.pdf. Accessed Sep 17, 2018.

24. Culpepper L. An Introduction to the National Institutes of Health. Fam Med. 1984;16(2):64.

25. Hames CG. Evans County cardiovascular and cerebrovascular epidemiologic study. Introduction. Arch Intern Med. 1971;128(6):883-886.

26. Phillips TJ. Research considerations for the family physician. J Fam Pract. 1978;7(1):121-128.

27. Bryan JE. The Role of the Family Physician in America's Developing Medical Care Program. St. Louis, MO: Warren H. Green, Inc; 1968:18.

28. Cahal MF. Publisher's Memo. Amer Fam Phys/GP. 1970;1:7.

29. Holmes MH. A most practical periodical. GP. 1950;2(6):19-21.

30. Geyman JP. Climate for research in family practice. J Fam Pract. 1978;7(1):69-74.

31. McWhinney IR. Family medicine as a science. J Fam Pract. 1978;7(1): 53-58.

32. Stephens GG. The Intellectual Basis of Family Practice. Tucson, AZ: Winter Publishing Co; 1982:13.

33. Geyman JP. Editorial: Expanded literature base as a critical need in family practice. J Fam Pract. 1974;1(1):4.

34. Geyman JP. On entry into phase two in family practice development. J Fam Pract. 1977;4(1):15.

35. Burch GE. Of Research People. New York, NY: Grune \& Stratton; 1955:11.

36. Bryan JE. The Role of the Family Physician in America's Developing Medical Care Program. St. Louis, MO: Warren H. Green, Inc; 1968:8. 
37. Culpepper L, Franks P. Family medicine research. Status at the end of the first decade. JAMA. 1983;249(1):63-68.

38. Stephens GG. The intellectual basis of family practice. J Fam Pract. 1975;2(6):423-428.

39. Pellegrino ED. The academic viability of family medicine. A triad of challenges. JAMA. 1978;240(2):132-135.

40. Spitzer W. The intellectual worthiness of family medicine. The Pharos. 1977:40(3):2-12.

41. Family doctor specialty born at last. Med World News. 1969;10(2):15.

42. Dennis JL. The future of family practice in our medical schools. J Fam Pract. 1974;1(1):6-8.

43. Dennis JL. The establishment of family practice department in medical schools. Colorado GP. 1969;11(1):4-9.

44. Geyman JP. The Modern Family Doctor and Changing Medical Practice. New York, NY: Meredith Corporation; 1971:19.

45. Geyman JP. Family practice in evolution: progress, problems and projections. N Engl J Med. 1978;298(11):593-601.

46. Lucan SC, Phillips RL Jr, Bazemore AW. Off the roadmap? Family medicine's grant funding and committee representation at $\mathrm{NIH}$. Ann Fam Med. 2008;6(6):534-542.

47. Bowman MA, Lucan SC, Rosenthal TC, Mainous AG III, James PA. Family medicine research in the United States from the late 1960s into the future. Fam Med. 2017;49(4):289-295.

48. Peterson KA, Lipman PD, Lange CJ, Cohen RA, Durako S. Supporting better science in primary care: a description of practice-based research networks (PBRNs) in 2011. J Am Board Fam Med. 2012; 25(5):565-571.
49. Voorhees JR, Xierali IM, Bazemore AW, Phillips RL Jr, Jaén CR, Puffer JC. A small percentage of family physicians report time devoted to research. J Am Board Fam Med. 2013;26(1):7-8.

50. Stange KC. The problem of fragmentation and the need for integrative solutions. Ann Fam Med. 2009;7(2):100-103.

51. Stange KC, Miller WL, McWhinney I. Chapter 7. Developing the knowledge base of family practice. In: Green LA, Graham R, Frey JJ, Stephens GG, eds. Keystone III. The Role of Family Practice in a Changing Health Care Environment. Washington, DC: The Robert Graham Center; 2001:196.

52. Jaén CR. Uncloaking family medicine research: So much to know, so little time.... J Am Board Fam Med. 2013;26(1):5.

53. Green LA. The research domain of family medicine. Ann Fam Med. 2004;2(Suppl 2):S23-S29.

54. Ewigman B, Davis A, Vansaghi T, et al. Building research \& scholarship capacity in departments of family medicine: A new joint ADFM-NAPCRG initiative. Ann Fam Med. 2016;14(1):82-83.

55. deGruy FV III, Ewigman B, DeVoe JE, et al. A plan for useful and timely family medicine and primary care research. Fam Med. 2015; 47(8):636-642.

56. Peek CJ, Glasgow RE, Stange KC, Klesges LM, Purcell EP, Kessler RS. The 5 R's: an emerging bold standard for conducting relevant research in a changing world. Ann Fam Med. 2014;12(5):447-455.

\section{Get the Annals of} Family Medicine by E-mail

SEPTEMBER/OCTOBER 2018 * Vol 16, No. 5

Editorials । Original Research I Research Briefs I Systematic Reviews I Reflections I Innovations | Departments

\section{Editorial Fellowship: Now accepting applications}

The full text of the journal is available online at hitto://www. annfammed.org and through various ggregators, including PubMed Central, EBSCO, and MDConsult. The Annals is indexed in the MEDLINE, Science Citation Index Expanded, Current Contents/Clinical Medicine, EMBASE, and CINHAL databases.

\section{EDITORIALS}

In This Issue: Nothing Simple Kurt C. Stange

The Long Loneliness of Primary Carey Timothy P. Daaleman

Clinical Prediction Rules: Challenges, Barriers, and Promises Emma Wallace; Michael E. Johansen

\section{ORIGINAL RESEARCH}

Social Isolation and Patient Experience in Older Adults

Takuya Aoki; Yosuke Yamamoto; Tatsuyoshi Ikenoue; Yuka Urushibara-Miyachi; Morito Kise; Yasuki Fujinuma; Shunichi Fukuhara

Social isolation is associated with a negative patient experience in older primary care patients in Japan. 